Thorax (1968), 23, 261.

\title{
Strangulation of the heart following intrapericardial pneumonectomy
}

\author{
M. H. YACOUB, W. G. WILLIAMS, AND A. AHMAD \\ From the Brompton Hospital, London S.W.3
}

\begin{abstract}
Two cases of strangulation of the heart following left intrapericardial pneumonectomy are described. The condition presents in the immediate post-operative period by sudden fall of blood pressure associated with a high central venous pressure. The diagnosis is usually made by the characteristic radiographic appearances. Actual strangulation of the ventricles is more common on the left side and can lead to irreversible damage in a short time. The predisposing and precipitating factors are discussed with special reference to prevention. Treatment of the established case is by emergency thoracotomy and reduction of the herniated heart. Recurrence is prevented by repairing the defect or wide excision of the pericardium.
\end{abstract}

Strangulation of the heart is a serious complication of intrapericardial pneumonectomy, and it is usually fatal if not diagnosed and promptly corrected. Bettman and Tannenbaum (1948) were the first to describe this complication following left pneumonectomy. Higginson (1953) showed that it can also occur after right pneumonectomy. Fatal strangulation of the heart through a congenital pericardial defect was described as early as 1877 by Boxall. The condition has also been reported following crush injury of the chest (Beck, 1947). Prevention and treatment depend on an understanding of the factors that predispose to, and precipitate, herniation, as well as those that prevent spontaneous reduction of the heart and so lead to incarceration or strangulation of the ventricles. In this paper two cases of strangulation of the heart following left pneumonectomy are described, and the previously reported cases are analysed. The possible factors concerned in inducing herniation of the heart are discussed with special reference to prevention and treatment.

\section{CASE REPORTS}

CASE 1 A man aged 67 years was found to have carcinoma of the left upper lobe of the lung. Left intrapericardial pneumonectomy was performed on 19 May 1966. At operation the tumour was found to be infiltrating the pericardium around the pulmonary veins, necessitating excision of a large piece of pericardium. Immediately after operation he had a low blood pressure, tachycardia, and a high central venous pressure. His condition did not improve after blood transfusion and vasopressor drugs. A chest radiograph (Fig. 1) showed an ill-defined opacity in the lower part of the pneumonectomy space. The electrocardiogram showed wide QRS complexes and depression of ST segments. Over the next 24 hours his condition continued to deteriorate. On reviewing the post-operative radiographs the diagnosis of herniation of the heart was suggested and the patient was taken back to the operating theatre. At that stage he had all the signs of a critically low cardiac output. When the chest was reopened, the pericardium was found to have retracted behind the heart, holding it erect in the pneumonectomy space with the apex touching the chest wall. The herniated part of the heart was swollen and covered by oedematous pericardial fat. The heart was reduced into the pericardial cavity after slitting the lower part of the pericardium. This produced immediate improvement of the circulation. The defect in the pericardium was repaired using a patch of pleura. Progressive deterioration of the patient's condition resulted in death while the chest was being closed.

Comment Strangulation of the ventricles by the sharp edge of the pericardial defect resulted in severe myocardial damage evidenced by the abnormal electrocardiogram and appearance of the heart at operation. This resulted in death.

CASE 2 A man aged 72 years was found to have undifferentiated carcinoma of the left lower lobe of the lung. Intrapericardial pneumonectomy was performed on 17 October 1966. At operation the growth involved the lower vein, the pericardium surrounding the hilum, and the sheath of the aorta. The involved pericardium with a surrounding safety margin was excised. The resulting defect measured $15 \times 10 \mathrm{~cm}$. This was repaired with a patch of parietal pleura taken from the front of the chest wall. The chest was 

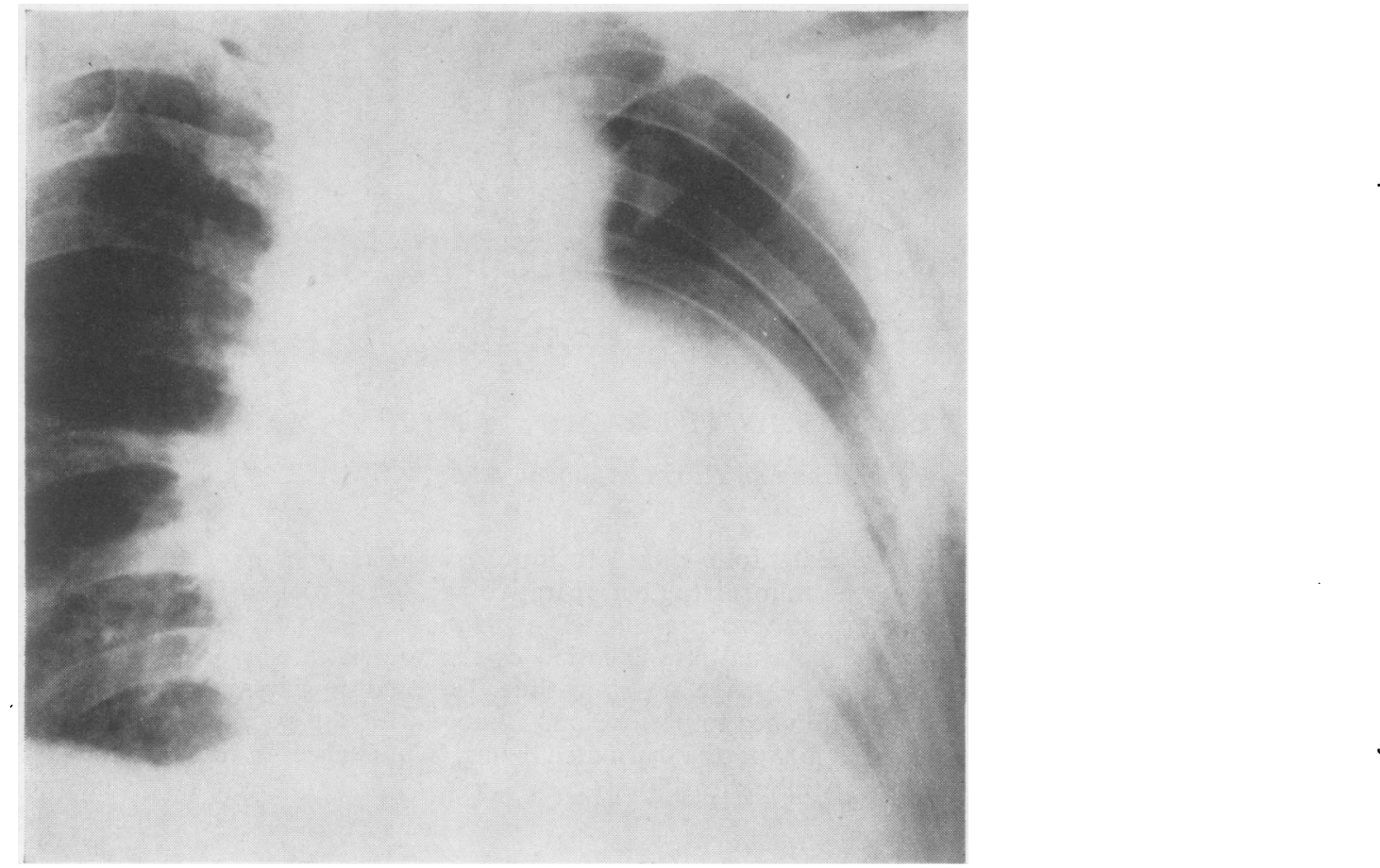

FIG. 1. Case 1. Chest radiograph showing a shift of the cardiac shadow to the left with a round, ill-defined upper border of the herniated ventricles.

FIG. 2. Case 2. Chest radiograph showing the characteristic appearances of herniation of the heart (see text). 
drained using an intercostal tube that was kept clamped and was released for half a minute every hour. Twelve hours after operation he became distressed and the blood pressure fell to $70 / 50 \mathrm{~mm}$. Hg. This lasted for five minutes and subsided spontaneously. Eight hours later he again became distressed and the blood pressure was unrecordable. The electrocardiogram showed wide QRS complexes with elevated ST segments. A few minutes later he developed ventricular fibrillation which was treated by cardiac massage and defibrillation after correcting the metabolic acidosis. The electrocardiogram continued to show left bundle-branch block and elevation of the ST segment. A chest radiograph (Fig. 2) showed a shift of the cardiac shadow to the left with an illdefined opacity in the left hemithorax. A diagnosis of strangulation of the heart was made and the patient was taken to the theatre, where he developed another attack of cardiac arrest. The chest was opened quickly and the heart was found to be strangulated as in case 1. The thin pleural flap used for the repair of the pericardial defect was torn from its place and had not prevented herniation. Cardiac massage and defibrillation resulted in a co-ordinated beat. The pericardial defect was repaired using thick pleura taken from the posterior chest wall above the diaphragm. Metabolic acidosis was corrected and an adrenaline drip was used to stimulate the heart, but the patient died a few hours later.

\section{DISCUSSION}

Radical pneumonectomy (Brock, 1948) for carcinoma of the bronchus includes excision of some pericardium around the pulmonary veins. This results in a small pericardial defect which is usually harmless. In some cases wider excision of the pericardium is necessitated by the proximity of the growth or actual infiltration of the pericardium. The resulting defect may predispose to herniation of the heart. This complication has been reported on both sides of the chest (Table) and it has been suggested that herniation is more common than is recognized (Kirchhof, 1951; Dahlbäck and Nilsson, 1956). It usually occurs shortly after operation and presents with a sudden fall in blood pressure associated with chest pain, cyanosis, tachycardia, and a raised central venous pressure. The electrocardiogram may show severe ischaemic changes as in our two patients. Ventricular fibrillation may occur, as in the case reported by Walmsley (1961) and in case 2 reported in this paper. The diagnosis is usually made by the radiographic appearances. On the left side, these include a shift of the cardiac shadow to the left with an ill-defined round opacity produced by the herniated, rapidly beating ventricles held over a shelf of pericardium. On the right side, the appearances of rotation of the heart into the right hemithorax are unmistakable (Fig. 10 in Higginson's paper, 1953). The most important point in diagnosis is to be aware of the condition.

The harmful effects of this complication are due to the altered position of the heart and great

T A B L E

\begin{tabular}{|c|c|c|c|c|c|c|c|}
\hline Author & Sex & Age & Side & Time of Onset & $\begin{array}{l}\text { Inter- } \\
\text { costal } \\
\text { Tube }\end{array}$ & Precipitating Cause & Outcome \\
\hline $\begin{array}{l}\text { Bettman and Tannenbaum } \\
\text { (1948) }\end{array}$ & & 53 & Left & $\begin{array}{l}\text { Immediately after } \\
\text { operation (in theatre) }\end{array}$ & Present & $\begin{array}{l}\text { Rolling the patient on } \\
\text { to his left side }\end{array}$ & $\begin{array}{l}\text { Reoperation- } \\
\text { recovery }\end{array}$ \\
\hline Higginson (1953) & $\begin{array}{l}\mathbf{M} \\
\mathbf{M} \\
\mathbf{M} \\
\mathbf{M}\end{array}$ & $\begin{array}{l}? \\
? \\
? \\
?\end{array}$ & $\begin{array}{l}\text { Right } \\
\text { Right } \\
\text { Right } \\
\text { Right }\end{array}$ & $\begin{array}{l}\text { Immediately after } \\
\text { operation (in theatre) } \\
\text { No symptoms } \\
\text { As the skin was being } \\
\text { closed } \\
8 \text { hours post-op. }\end{array}$ & $\begin{array}{l}\text { Present } \\
? \\
?\end{array}$ & $\begin{array}{l}\text { Pressure inflation of } \\
\text { left lung and suction } \\
\text { on drainage tube } \\
- \\
\text { Tracheal suction }\end{array}$ & 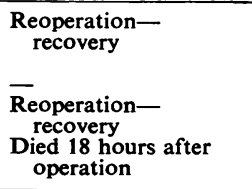 \\
\hline Kirchhof (1951) & $\mathbf{M}$ & 41 & Right & $\begin{array}{l}\text { While the chest was } \\
\text { being closed }\end{array}$ & $?$ & - & $\begin{array}{l}\text { Chest reopened- } \\
\text { recovery }\end{array}$ \\
\hline $\begin{array}{l}\text { Dahlbäck and Nilsson } \\
\text { (1956) }\end{array}$ & $\mathbf{M}$ & 69 & Right & $\begin{array}{c}\text { Immediately after } \\
\text { operation }\end{array}$ & Present & $\begin{array}{l}\text { Suction on drainage } \\
\text { tube }\end{array}$ & $\begin{array}{l}\text { Chest reopened- } \\
\text { recovery }\end{array}$ \\
\hline Sharma et al. (1959) & $\begin{array}{l}\mathbf{M} \\
\mathbf{M}\end{array}$ & $\begin{array}{l}66 \\
31\end{array}$ & $\begin{array}{l}\text { Left } \\
\text { Left }\end{array}$ & $\begin{array}{l}\text { Immediately after } \\
\text { operation } \\
\text { Immediately after } \\
\text { operation }\end{array}$ & $\begin{array}{l}\text { Present } \\
\text { Present }\end{array}$ & - & $\begin{array}{l}\text { Died } 30 \text { hours after } \\
\text { operation } \\
\text { Reoperation-died } 31 \\
\text { hours after initial } \\
\text { pneumonectomy }\end{array}$ \\
\hline Present series & $\begin{array}{l}\mathbf{M} \\
\mathbf{M}\end{array}$ & $\begin{array}{l}67 \\
72\end{array}$ & $\begin{array}{l}\text { Left } \\
\text { Left }\end{array}$ & $\begin{array}{l}\text { Immediately after } \\
\text { operation } \\
12 \text { hours post-op. }\end{array}$ & $\begin{array}{l}\text { Present } \\
\text { Present }\end{array}$ & $\begin{array}{l}- \\
-\end{array}$ & $\begin{array}{l}\text { Reoperation-died } 28 \\
\text { hours after initial } \\
\text { pneumonectomy } \\
\text { Reoperation-died } 24 \\
\text { hours after operation }\end{array}$ \\
\hline
\end{tabular}




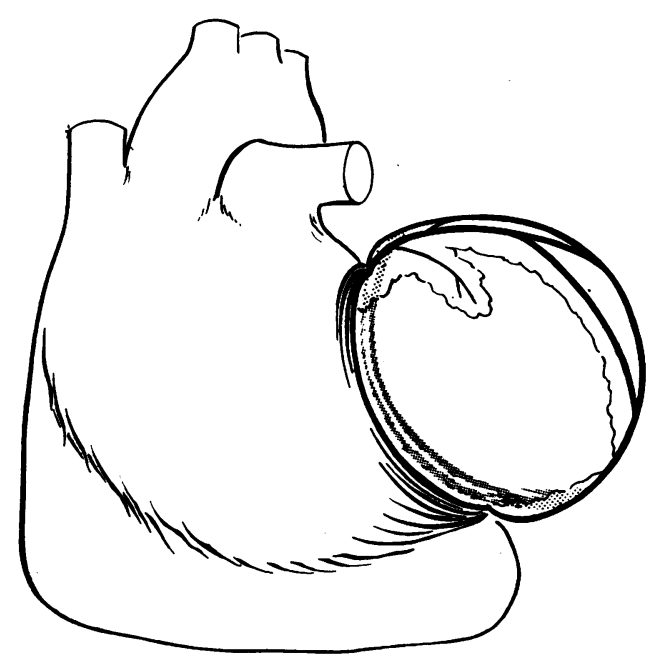

F1G. 3. Diagram to illustrate strangulation of the heart by pericardium on the left side.

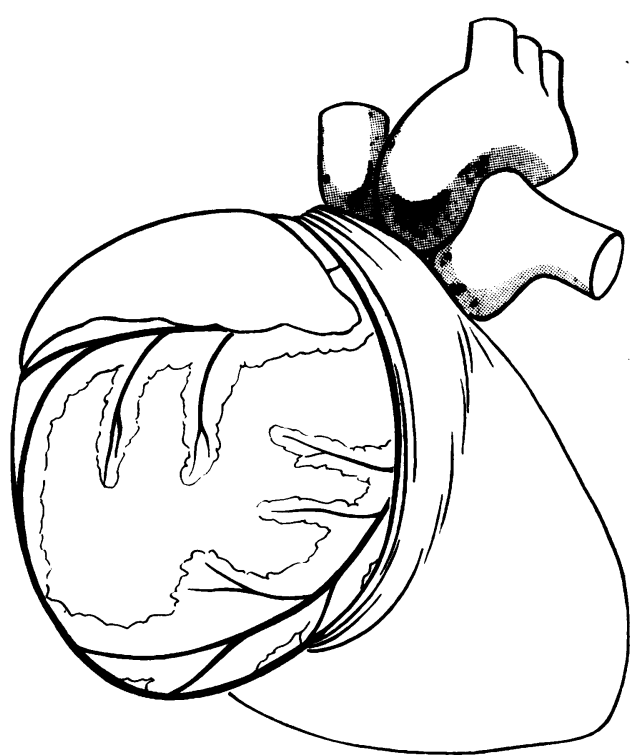

FIG. 4. Diagram to illustrate herniation of the heart on the right side.

vessels (Figs 3 and 4) as well as actual strangulation of the heart in a high proportion of cases. Beck (1947) has shown experimentally that the heart tolerates angulation and rotation badly. This is probably due to kinking of the outflow of the heart and of the origin of the great vessels. On the left side, the most dangerous defects are medium-sized ones in the upper half of the pericardium, as the heart may herniate and become incarcerated by the edge of the pericardium. Apart from the abnormal position of the heart, the major factor in interfering with cardiac function is strangulation of the ventricles by the edge of the pericardium. This is usually manifested by severe venous congestion on the surface of the herniated ventricle, with oedema of epicardial fat and myocardium. Histological examination (Bruning, 1962) shows oedema and necrosis of the myocardium. These changes can produce irreversible damage in a short time. On the right side herniation of the heart can occur with large or moderatesized defects. In these cases there is anti-clockwise rotation of the heart with the apex lying well into the right hemithorax (Fig. 4). Spontaneous reduction is prevented by the sternum. The main harmful effect is due to rotation of the heart. Strangulation of the ventricles by the edge of the pericardial defect may be an additional factor, but is not a constant feature as it is on the left side.

Apart from the size and site of the pericardial defect, other factors may predispose to the condition; these include drainage of the pneumonectomy space and absence of pericardial adhesions. Precipitating factors include suction on the drainage tube (Higginson, 1953; Dahlbäck and Nilsson, 1956 ; Walmsley, 1961), rolling the patient on to the operated side (Bettman and Tannenbaum, 1948 ; Higginson, 1953), tracheal suction or violent bouts of coughing. Inflation of the remaining lung may also be a factor.

Fatal herniation of the heart through congenital pericardial defects has been described only on the left side (Boxall, 1877; Sunderland and Wright Smith, 1944 ; Bruning, 1962). In all three cases, the defect was situated in the upper part of the pericardium. The patient described by Boxall was a woman aged 28 years who died suddenly three days post-partum with symptoms suggestive of $N$ 'pulmonary embolism'. Sunderland and Wright Smith (1944) described a boy aged 2 years who suddenly became distressed while playing with an older boy and died 14 hours later. The patient described by Bruning (1962) was a 7-year-old boy who had a short coughing attack, became immediately unconscious, and died 15 minutes later. In all three cases the necropsy showed strangulation of the heart with almost identical findings to those found in cases occurring after pneumonectomy. Fatal herniation of the heart has not been reported in patients with complete absence of the 
left pericardium, as in these cases the heart is free to move in the common pleuro-pericardial cavity and does not get strangulated.

Treatment of this complication is mainly prophylactic. On the left side wide excision of the pericardium effectively prevents incarceration. However, the protective function of the parietal pericardium is lost. The possible haemodynamic effects of absence of the pericardium were recently discussed (Tubbs and Yacoub, 1968). Moderately small defects can be repaired using a patch of parietal pleura (Tubbs, 1966). Strong pleura should be used for this purpose ; the pleura lining the posterior part of the lower chest is often thickened and can be conveniently used. Thin pleura should never be used because it can be torn by the vigorously beating heart as it was in case 2 . On the right side wide excision of the pericardium prevents strangulation by the pericardial edge but does not abolish the risk of fatal incarceration of the heart, as in one of the cases described by Higginson (1953). These defects should be repaired by strong pleura whenever possible. Treatment of the established case is an emergency operation, reduction of the heart into the pericardial sac, and excision or repair of the pericardium.
We should like to thank Mr. O. S. Tubbs and Mr. M. Paneth for their encouragement to publish details of these patients who were under their care. We are also grateful to Mrs. Carol Dawbarn, medical artist at the National Heart Hospital, for preparing the diagrams.

\section{REFERENCES}

Beck, C. S. (1947). Pressures on heart. Sth. Surg., 13, 348.

Bettman, R. B., and Tannenbaum, W. J. (1948). Herniation of the heart through a pericardial incision. Ann. Surg., 128, 1012.

Boxall, R. (1877). Incomplete pericardial sac. Escape of heart into left pleural cavity. Trans. Obst. Soc. (Lond.), 28, 209.

Brock, R. C. (1948). Bronchial carcinoma. Brit. med. J., $2,737$.

Bruning, E. G.l H. (1962). Congenital defect of the pericardium. J. clin. Path., 15, 133.

Dahlbäck, O., and Nilsson, E. (1956). Incarceration of the heart following right pneumonectomy. Acta chir. scand., 110, 447.

Higginson, J. F. (1953). Block dissection in pneumonectomy for carcinoma. J. thorac. Surg., $25,582$.

Kirchhof, A. C. (1951).' Herniation of the heart. Report of a case. Anesthesiology, 12, 774.

Sharma, V. N., Bates, M., and Hurt, K. L. (1959). Herniation of the heart after lintrapericardial pneumonectomy for bronchial carcinoma. Thorax, 14, 36.

Sunderland, H., and Wright-Smith, R. S. (1944). Congenital pericardial defects. . Brit. Heart J., 6, 167.

Tubbs,' O. S. (1966). Personal communication. and Yacoub, M. H. (1968). Congenital defects of the pericardium. In preparation.

Walmsley, D. A. (1961). Herniation of the heart after intrapericardial pneumonectomy. Lancet, 1, 645. 